\title{
Change in multidimensional problems and quality of life over three months after HIV diagnosis: a multicentre longitudinal study in Kenya and Uganda
}

Victoria Simms ${ }^{1}$, Julia Downing ${ }^{2}$, Eve Namisango ${ }^{3}$, R. Anthony Powell ${ }^{4}$, Faith Mwangi-Powell ${ }^{4}$, Irene J. Higginson ${ }^{2}$ and Richard Harding ${ }^{2^{*}}$ (D)

\begin{abstract}
Background: Evidence on patient-reported outcomes of newly diagnosed HIV patients is scarce, and largely crosssectional. This prospective cohort study describes the prevalence of, and changes in, patient-reported outcomes in the three months after HIV diagnosis, in 11 HIV outpatient centres in Kenya and Uganda.

Methods: Adults were recruited within 14 days of result, completing self-report measures four times at monthly intervals. Multilevel mixed-effects linear regression (quality of life continuous outcomes) and ordinal logistic regression (symptoms and concerns categorical outcomes) modelled change over time, with repeated observations grouped within individuals adjusted for demographic/clinical characteristics, and multiple imputation for missing data.
\end{abstract}

Results: 438 adults were enrolled and 234 (53.4\%) initiated ART. Improvement was found for MOS-HIV physical health (from 46.3 [95\% Cl 45.1-47.3], to 53.7 [95\% Cl 52.8-54.6], $p<0.001$ ), and mental health (from 46.4 [95\% Cl 45.5-47.3] to 54.5 [95\% Cl 53.7-55.4], $\mathrm{p}<0.001)$. POS subscale 'interpersonal problems' improved but remained burdensome $(\mathrm{OR}=$ $0.91,95 \% \mathrm{Cl}=0.87-0.94, \mathrm{p}<0.001 ; 22.7 \%$ reported severe problems at final time point). The scores for the existential POS subscale $(\mathrm{OR}=0.95,95 \% \mathrm{Cl}=0.90-1.00, p=0.056)$ and physical/psychological problems POS subscale (OR $=0.97$, $95 \% \mathrm{Cl}=0.92-1.02, p=0.259)$ did not improve.

Participants who initiated ART had worsening physical/psychological $(\mathrm{OR}=0.64,95 \% \mathrm{Cl}=0.41-0.99, \mathrm{p}=0.045)$ and interpersonal problems $(\mathrm{OR}=0.64,95 \% \mathrm{Cl}=0.42-0.96, \mathrm{p}=0.033)$.

Conclusion: Although some self-reported outcomes improve over time, burden of interpersonal problems remains substantial and existential concerns do not improve.

Keywords: HIV, Newly diagnosed, Patient-report, Adjustment

\section{Background}

Increasing numbers of people will test HIV positive and enter care due to efforts made to meet the UNAIDS 9090-90 targets of $90 \%$ of people with HIV in care, $90 \%$ of those in care on antiretroviral therapy, and $90 \%$ of treated patients virally suppressed [1]. In resource-constrained settings where the HIV disease burden is greatest, health

\footnotetext{
* Correspondence: richard.harding@kcl.ac.uk

2King's College London, Florence Nightingale Faculty of Nursing Midwifery and Palliative Care, Cicely Saunders Institute, Department of Palliative Care, Policy and Rehabilitation, Bessemer Road, London SE5 9PJ, England Full list of author information is available at the end of the article
}

systems and providers are under pressure, and a paradigm shift is needed to enable an adequate, sustainable response [2]. In order to achieve viral suppression, patients are required to adhere to ART and remain engaged with treatment and care facilities. The current model of HIV care is delivered in overstretched systems with weak infrastructure and high patient numbers, and these challenges have been associated with attrition from ART programmes [3].

People recently diagnosed with HIV report physical [4], psychological [5] and social support problems [6]. These problems have been identified by HIV outpatients in East Africa as contributors to poor attendance and

(c) The Author(s). 2019 Open Access This article is distributed under the terms of the Creative Commons Attribution 4.0 International License (http://creativecommons.org/licenses/by/4.0/), which permits unrestricted use, distribution, and reproduction in any medium, provided you give appropriate credit to the original author(s) and the source, provide a link to the Creative Commons license, and indicate if changes were made. The Creative Commons Public Domain Dedication waiver (http://creativecommons.org/publicdomain/zero/1.0/) applies to the data made available in this article, unless otherwise stated. 
treatment adherence [7]. In a South African study of people recently diagnosed with HIV, $14.8 \%$ met the criteria for post-traumatic stress disorder, which is associated with worse functional health status [8]. This may limit patients' ability to absorb information and make critical decisions about their care [9]. Conversely, the phenomenon of post-traumatic growth has also been described among people diagnosed with serious health conditions, and the individual may report improved relationships, enhanced appreciation for life, and a greater sense of personal strength [10].

A systematic review concluded that the lack of longitudinal studies has prevented understanding of the individual response to a HIV diagnosis over time, in terms of quality of life, physical and psychosocial outcomes [11]. A number of gaps were identified in the evidence, principally: lack of measures of emotional support needs, omission of spiritual distress, lack of studies that recruited outpatients in low-income countries, use of staff proxy rather than self-report, lack of measurement of problems across domains, small sample sizes, lack of repeated measures to appraise adjustment to diagnosis, and no longitudinal analysis methods.

Our cross-sectional analysis of 438 adults newly diagnosed with HIV (i.e. within 14 days) in 11 outpatient centres in Kenya and Uganda reported the following main problems: help and advice $(64.7 \%$ scoring at the worst end of the scale, i.e., $4-5$ on a scale of $0-5$ ); sharing feelings (53.0\%); spiritual distress (19.2\%); feeling life is not worthwhile $(10.0 \%)$ [12]. For these problems and additional measures of health-related quality of life, all outcomes were independent of CD4 count or ART eligibility. To retain these individuals in care, we must understand how their problems change immediately following diagnosis so that responsive care can be planned.

The aim of this paper is to measure change in patient-reported outcomes in the first three months following HIV diagnosis. The study objectives were to: i) determine eligibility for ART at diagnosis and uptake in the 3 months following diagnosis; ii) measure change in patient-reported outcomes, iii) identify clinical and demographic predictors of change.

\section{Methods}

\section{Design}

A secondary analysis was carried out on longitudinal data from an observational cohort study conducted by the authors as part of a mixed-methods evaluation of care and support for the President's Emergency Plan for AIDS Relief (PEPFAR). The study protocol has previously been published [13]. The full cohort consisted of approximately 120 adult HIV-positive outpatients from each of 12 rural and urban health facilities in Kenya and Uganda, enrolled in 2008 by consecutive sampling and interviewed four times at monthly intervals [14]. The inclusion criteria were age 18 or over; aware of their HIV diagnosis; and being new to care or presenting with a new problem/symptom [13, 15]. Of these 1337 participants, those enrolled within 14 days following their HIV diagnosis were selected for this secondary analysis.

\section{Procedure}

438 participants were enrolled within 14 days following their HIV diagnosis at one of 11 clinical settings in Kenya and Uganda (the twelfth had no newly diagnosed patients), and were included in this analysis. Participants were either diagnosed at the health facility where the study was based, or diagnosed at a smaller health post/ mobile testing centre and referred to the recruiting facility for their HIV care.

Self-report data using validated patient-centred outcome measures were collected at baseline and for 3 subsequent monthly time points. The MOS-HIV (Medical Outcomes Scale for HIV) is a widely used 35-item health-related quality of life questionnaire [16] validated in many countries including Uganda [17, 18]. Multidimensional problems (physical, psychological, social and spiritual) were measured using the APCA African Palliative Outcomes Scale (POS), designed and validated in sub-Saharan Africa [19]. The POS is a 10-item Likert questionnaire about multidimensional problems in the previous 3 days, with each item scored $0-5$. A demographic questionnaire was completed at baseline only, and the date and results of a CD4 test (up to six months after HIV diagnosis) and World Health Organization (WHO) HIV stage were extracted from patients' records. Baseline data collection also included the ECOG, a widely used single item measure of physical function [20]. Questionnaires were translated from English into Swahili, Luo, Luganda and Runyakitara, then piloted.

\section{Analysis}

Analysis was conducted using Stata v14.0. MOS-HIV item scores were converted into continuous 0-100 summary scores for mental and physical health, with higher scores indicating better health $[17,21]$. The POS was analysed using three previously validated factors: phys$\mathrm{ical} /$ psychological well-being, interpersonal well-being, and existential well-being [22, 23]. Poverty quintile was calculated in line with the DHS method using variables including house construction, possession of items, and fuel supply [24]. APCA African POS factors were categorised into mild/none (score $0-4$ ), moderate problems $[5-7]$ and severe problems $(\geq 8)$. The time variable was defined as number of weeks since enrolment in care. Interviews were scheduled for one month apart but participants frequently attended at longer intervals, so actual time was used rather than number of visits. Visits more 
than 20 weeks after enrolment were excluded as outliers. Multilevel mixed-effects linear regression with robust standard errors was used to fit models for the subscale continuous variables physical health score and mental health score, with observations grouped within individuals. For the ordinal POS factor variables, multilevel mixed-effects ordinal logistic regression was used. Co-variates were selected a priori and were either binary (gender, ART initiation, country) or ordinal, fitted as continuous (age category, physical function, poverty quintile). ART initiation was defined as having initiated ART during follow-up. To impute missing data we used multiple imputation with 10 iterations on the same covariates plus baseline score, having set the data as cross-sectional time series with individual ID to identify the person and time since enrolment for the time.

\section{Results}

\section{Sample characteristics}

Baseline characteristics of the sample have been previously described in detail [12]. Of the 438 newly diagnosed participants, $270(61.6 \%)$ were women, the age range was 18-59 (mean 32.9); just over half $(56.4 \%, n=$ 247 ) were enrolled in Kenya. Age distribution was 20.3\% aged $18-25,63.0 \%$ aged $26-40$ and $16.7 \%$ aged $41-59$. The majority $(69.9 \%, n=306)$ were physically fully active (ECOG score 0$)$, with $23.3 \%(n=102)$ scoring 1 and $6.8 \%(\mathrm{n}=30)$ scoring more than 1 . WHO stage was obtained for 198 participants, with 26\% Stage I, 36\% Stage II, 31\% Stage III and 7\% Stage IV.

Within 20 weeks, out of 438 participants, 52 (11.9\%) completed only one interview, 31 (7.1\%) completed two, $33(7.5 \%)$ completed three and $322(73.5 \%)$ completed all four (Fig. 1), making 1501 research data collection visits out of a possible 1752 (85.7\%). Out of 1501 visits, 438 were on the day of enrolment, by definition. 332 (22.1\%) were 1-40 days after enrolment, 405 (27.0\%) 4180 days after enrolment, $312(20 \cdot 8 \%)$ 81-120 days after enrolment and $14(0 \cdot 9 \%)$ 121-242 days after enrolment.

\section{Attendance and treatment}

ART eligibility was not directly recorded at data collection so it was inferred later based on CD4 count and WHO stage where these were available. In line with the national guidelines in use at the time of data collection, patients with a CD4 count below 350 cells/ $\mu$ l or a WHO stage 4 were eligible for ART [25]. Patients with both CD4 count $\geq 350$ cells $/ \mu$ and WHO stage $1-3$ were not eligible. Using these criteria, ART eligibility could be established for 263/438 people (Table 1). 207 (78.7\%) were eligible for ART at enrolment (CD4 $<350$ or WHO stage 4). Out of 207 participants eligible for ART, 154 (74.4\%) initiated ART within the study period and 53 (25.6\%) did not. Of the 53 who did not initiate,16 only

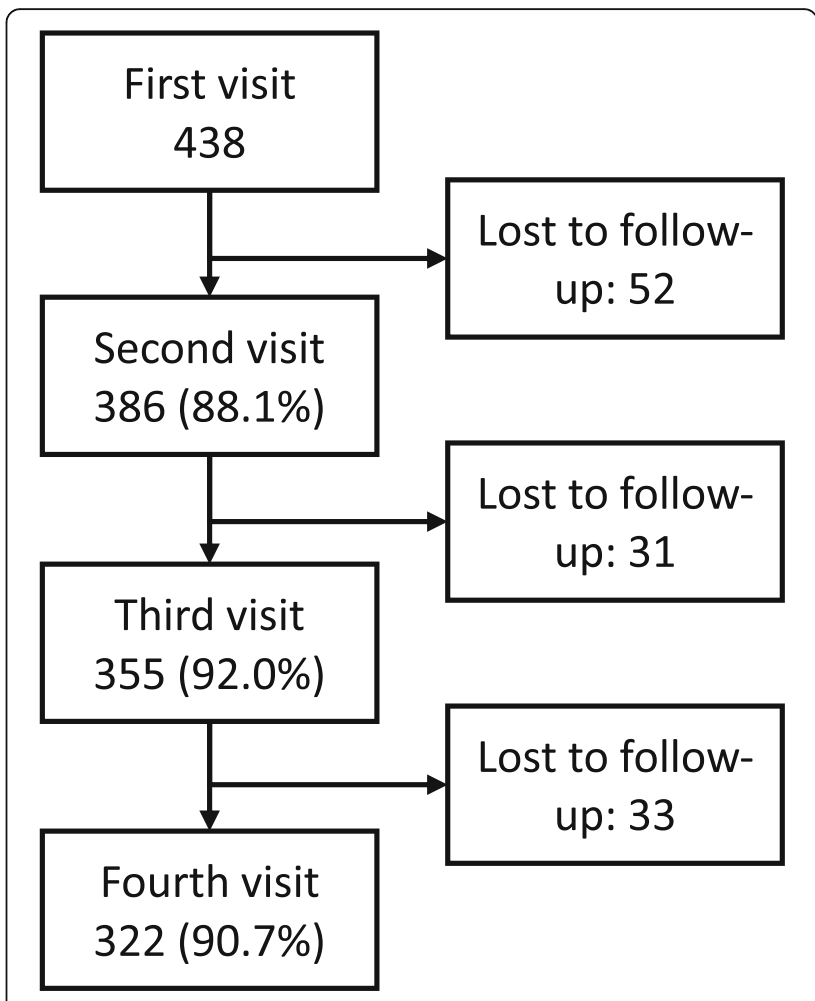

Fig. 1 Number of participants per visit

attended one appointment at the facility and another 8 dropped out before completing all 4 appointments. For 5/53 who did not initiate ART, their CD4 test was delayed, so their eligibility was not confirmed during follow-up. 21 people took ART at least once despite not being eligible according to CD4 count and WHO stage. Out of 175 participants whose ART eligibility was unknown according to available data on file, 59 initiated ART.

\section{Change in patient-reported outcomes}

Participants with fewer than 3 follow-up observations had mean baseline physical and mental health scores 3 points lower than those of participants who had no missing data, and were also more likely to report Existential problems.

At baseline, mean score on the physical health score of the MOS-HIV was 46.3 (standard deviation 12.0). Mental health score at baseline was 46.4 (standard deviation 9.9). A multi-level model with no covariates except for

Table 1 ART eligibility and initiation

\begin{tabular}{llll}
\hline & Initiated ART $\mathrm{n}$ & Never initiated $\mathrm{n}$ & Total $\mathrm{n}$ \\
\hline Eligible & 154 & 53 & $207(47 \cdot 3 \%)$ \\
Not eligible & 21 & 35 & $56(12.8 \%)$ \\
Eligibility unknown & 59 & 116 & $175(40.0 \%)$ \\
Total & $234(53.4 \%)$ & $204(46.6 \%)$ & $438(100 \%)$ \\
\hline
\end{tabular}


time showed that physical health score improved by 0.5 per week (95\% CI 0.4-0.6) and mental health score by 0.6 per week (95\% CI 0.5-0.6).

The prevalence of severe and moderate problems as measured by the POS decreased over time for all subscales (Fig. 2). However, interpersonal problems were the most pervasive. Even after four clinic visits 74/326 (22.7\%) participants still reported severe interpersonal problems and less than half (43.6\%) reported mild/no problems.

After controlling for sociodemographic and health factors, on the MOS-HIV subscales, mental and physical health scores both improved over time after recruitment into care. On POS, Interpersonal problems subscale improved over time. Existential problems improved, but with only borderline significance $(p=0.056)$. No statistically significant improvement was found for the phys$\mathrm{ical} /$ psychological subscale.

\section{Predictors of change on patient-reported outcomes}

Limited physical function at baseline was associated with worsening physical health score but improvement in the interpersonal subscale (Table 2). Older age was associated with improvement in mental health score and existential problems over time. Gender was not associated with any outcome.
Compared to the economically poorest, those with greater wealth were likely to have improved physical and mental health score and fewer physical/psychological or existential problems over time. Compared to Kenya, participants in Uganda had less improvement in physical or mental health score over time, and more physical/psychological and existential problems.

With respect to ART, initiation during the study period was not associated with improvement in physical or mental health scores or existential problems, but was associated with improvement in both physical/psychological problems and interpersonal problems.

\section{Discussion}

This novel longitudinal multi-centred cohort study found that, for adults newly diagnosed with HIV infection in East Africa, statistically significant improvement was found for both physical and mental health-related quality of life (when controlling for patient characteristics). While there was also improvement in interpersonal and existential problems, no statistically significant improvement was found for physical/psychological problems.

This study has advanced the evidence by addressing the conclusions of a systematic review which revealed an absence of data to determine how people newly diagnosed with HIV change in their self-report health status

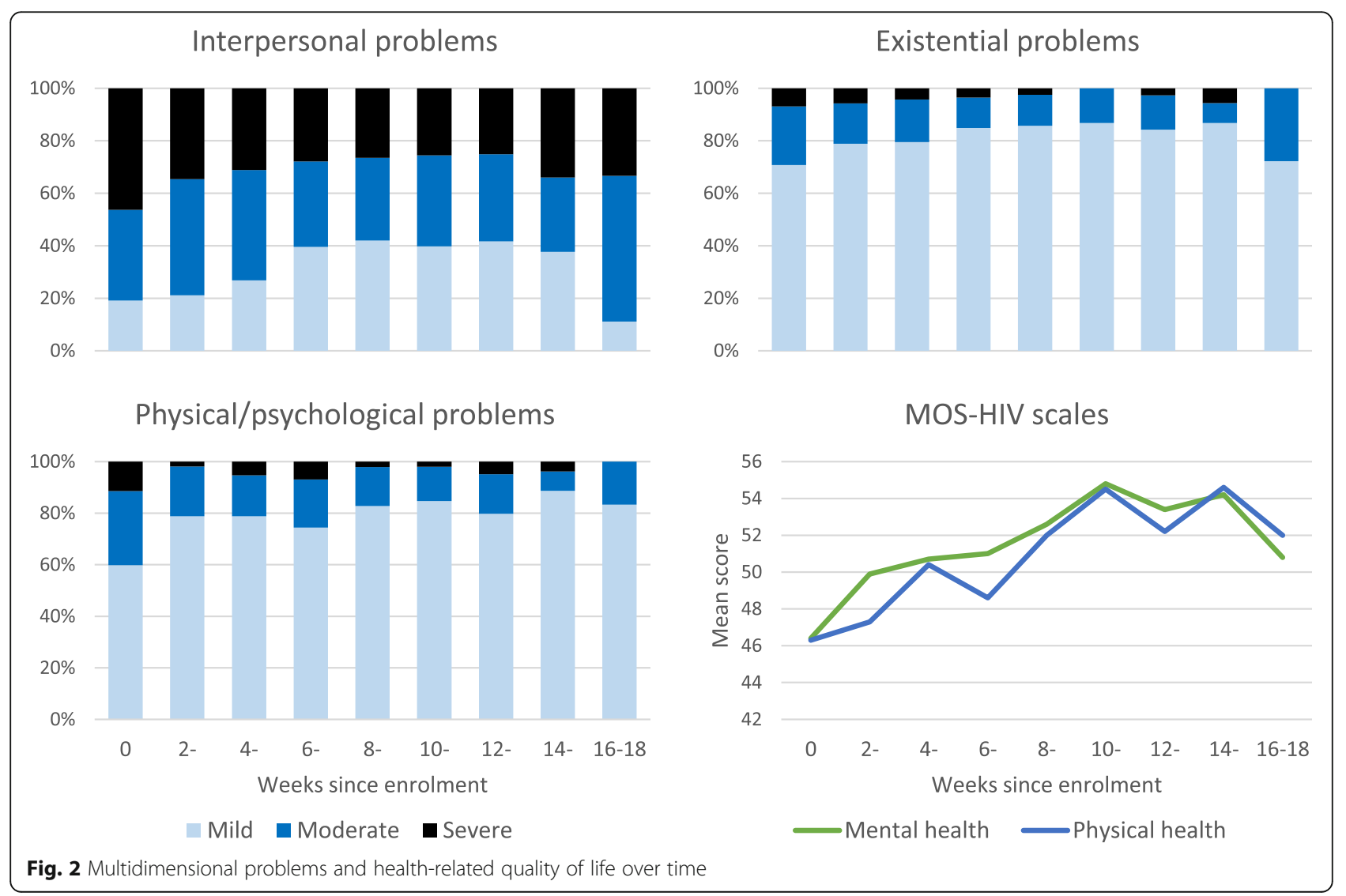


Table 2 Mixed-effects models for multidimensional problems and health-related quality of life over time

\begin{tabular}{|c|c|c|c|c|c|c|c|c|c|c|c|}
\hline \multirow[b]{2}{*}{ Variable } & \multirow[b]{2}{*}{ Reference group } & \multicolumn{2}{|c|}{ physical health score } & \multicolumn{2}{|c|}{ mental health score } & \multicolumn{2}{|c|}{$\begin{array}{l}\text { APCA POS Physical/ } \\
\text { psych. Problems }\end{array}$} & \multicolumn{2}{|c|}{$\begin{array}{l}\text { APCA POS } \\
\text { Interpersonal problems }\end{array}$} & \multicolumn{2}{|c|}{$\begin{array}{l}\text { APCA POS } \\
\text { Existential problems }\end{array}$} \\
\hline & & Coeff $(95 \%$ Cl) & $\mathrm{p}$ & Coeff (95\% Cl) & $\mathrm{p}$ & OR $(95 \% \mathrm{Cl})$ & $\mathrm{p}$ & OR 95\% Cl) & $\mathrm{p}$ & OR $(95 \% \mathrm{Cl})$ & $\mathrm{p}$ \\
\hline Week & 0 & $\begin{array}{l}0.28(0.16 \\
0.40)\end{array}$ & $<0.001$ & $\begin{array}{l}0.35(0.25 \\
0.45)\end{array}$ & $<0.001$ & $\begin{array}{l}0.97 \\
(0.92,1.02)\end{array}$ & 0.259 & $\begin{array}{l}0.91 \\
(0.87,0.94)\end{array}$ & $<0.001$ & $\begin{array}{l}0.95 \\
(0.90,1.00)\end{array}$ & 0.056 \\
\hline $\begin{array}{l}\text { Physical } \\
\text { function }\end{array}$ & Fully active & $\begin{array}{l}-8 \cdot 69 \\
(-10 \cdot 18,-7 \cdot 21)\end{array}$ & $<0.001$ & $\begin{array}{l}-4.93 \\
(-6.09,-3.76)\end{array}$ & $<0.001$ & $\begin{array}{l}4 \cdot 29 \\
(2 \cdot 94,6 \cdot 26)\end{array}$ & $<0.001$ & $\begin{array}{l}0.86 \\
(0.63,1 \cdot 19)\end{array}$ & 0.373 & $\begin{array}{l}2.92 \\
(1.89,4.50)\end{array}$ & $<0.001$ \\
\hline Gender & Male & $\begin{array}{l}0.81 \\
(-0.48,2.09)\end{array}$ & 0.218 & $\begin{array}{l}0.23 \\
(-1 \cdot 11,1 \cdot 58)\end{array}$ & 0.733 & $\begin{array}{l}1 \cdot 22 \\
(0.75,2 \cdot 00)\end{array}$ & 0.420 & $\begin{array}{l}0.92 \\
(0.59,1.44)\end{array}$ & 0.717 & $\begin{array}{l}0.69 \\
(0.39,1.23)\end{array}$ & 0.208 \\
\hline Age group & $18-25$ & $\begin{array}{l}0.50 \\
(-0.58,1.59)\end{array}$ & 0.365 & $\begin{array}{l}1.17(0.03 \\
2 \cdot 30)\end{array}$ & 0.045 & $\begin{array}{l}1.28 \\
(0.87,1 \cdot 87)\end{array}$ & 0.213 & $\begin{array}{l}0.76 \\
(0.54,1.09)\end{array}$ & 0.133 & $\begin{array}{l}0.65 \\
(0.41,1.03)\end{array}$ & 0.067 \\
\hline $\begin{array}{l}\text { Poverty } \\
\text { quintile }\end{array}$ & Poorest & $\begin{array}{l}0.46 \\
(0.04,0.88)\end{array}$ & 0.033 & $\begin{array}{l}0.38 \\
(-0.05,0.81)\end{array}$ & 0.082 & $\begin{array}{l}0.76 \\
(0.64,0.91)\end{array}$ & 0.002 & $\begin{array}{l}1 \cdot 19 \\
(1.02,1 \cdot 39)\end{array}$ & 0.031 & $\begin{array}{l}0.88 \\
(0.71,1.07)\end{array}$ & 0.204 \\
\hline ART & No ART & $\begin{array}{l}0.71 \\
(-0.51,1.92)\end{array}$ & 0.256 & $\begin{array}{l}1.44 \\
(0.11,2.76)\end{array}$ & 0.033 & $\begin{array}{l}0.51 \\
(0.31,0.82)\end{array}$ & 0.005 & $\begin{array}{l}0.61 \\
(0.39,0.95)\end{array}$ & 0.028 & $\begin{array}{l}0.86 \\
(0.49,1.52)\end{array}$ & 0.605 \\
\hline Country & Kenya & $\begin{array}{l}-0.98 \\
(-2 \cdot 19,0.24)\end{array}$ & 0.114 & $\begin{array}{l}-2.48 \\
(-3.81,-1.15)\end{array}$ & $<0.001$ & $\begin{array}{l}1 \cdot 70 \\
(1.07,2 \cdot 71)\end{array}$ & 0.026 & $\begin{array}{l}1.01 \\
(0.66,1.55)\end{array}$ & 0.969 & $\begin{array}{l}3.05 \\
(1.72,5 \cdot 42)\end{array}$ & $<0.001$ \\
\hline
\end{tabular}

over time [11]. This is timely, given the current policy to greatly increase the proportion of people infected with HIV who receive a test result, initiate therapy and remain in care to achieve viral suppression.

The association of POS scores and health-related quality of life outcomes with demographic variables at baseline have been presented previously in a cross-sectional study [12]. This study shows the association of variables with change over time, adjusting for baseline values. In the previous paper, the seven POS outcomes were analysed separately. Since then, factor analysis has determined the POS is composed of three factors [22], which have been used as outcomes here.

Our descriptive analysis showed that the prevalence of severe and moderate physical/psychological problems, as measured by the POS, decreased over time. This association, however, was no longer significant in the multivariate analysis after missing datapoints had been imputed through multiple imputation. There was a rise in prevalence of severe problems between the second and third follow-up visits, which may have weakened the association. Missingness was associated with lower baseline scores for physical and mental health. Without multiple imputation, most findings were similar but physical function was closely associated with all outcomes. The likely explanation is that participants with poor physical function were the most likely not to return.

Gender was not associated with any outcomes. In a longitudinal study of 1274 people with HIV in Uganda, women were at increased risk of poor mental health score (if on ART) and poor physical health score (if not initiated on ART) [26]. Depression was associated with worse physical health score over time, whether patients were on ART or not. There was no association between change in CD4 count over time and physical or mental health score [27], possibly because CD4 count was relatively high at baseline ( $>350$ for $80 \%$ of participants), or possibly because health scores reflect a more complex state of quality of life that is not closely tied to immunological function.

The Kenya population had a lower CD4 count distribution, although this is difficult to compare because almost half the Uganda sample did not have a CD4 count in the dataset. This challenge in lack of CD4 count on file has been previously reported [28], and is a concern for the current policy of increasing the proportion of eligible people on ART. The 11 sites varied in their settings, services and populations. Notably, two of the Uganda sites were TASO (The AIDS Support Organisation) centres, which may offer a different balance of services.

Interestingly, ART was not associated with improvement in physical health score over time, but there was an association with the physical/psychological problems and interpersonal problems subscales. This may reflect the relatively brief time period, and also any improvement in physical health due to viral suppression may have been offset by initial treatment-related side effects. It is important to note that while treatment did not in the short term improve existential problems, it was associated with improvement in interpersonal problems. This is likely due to the increased communication required to begin and maintain treatment.

Our study confirms earlier findings that health-related quality of life is worst at diagnosis and improves over the next 6 months [29]. However, our study sample is more representative of the population needing care than the previous study, as it is selected from men and women who registered at 11 sites after diagnosis through VCT, antenatal testing or as a result of illness. The study cited was of 160 women enrolled into a cohort while HIV-uninfected, who were diagnosed in the acute infection stage. 
The trauma of an HIV diagnosis can affect social functioning and mental health in addition to the implications for physical health, which may be as a result of the underlying infection or the psychosomatic impact of knowledge of HIV status. In a study in South Africa, 55\% of people with HIV had depressive symptoms just before their diagnosis [30]. Patients with depressive symptoms are less likely to have a CD4 test or to return for the result, which prevents or delays their entry into care [30]. We have demonstrated that while mental-health related quality of life improves in the three months following diagnosis, interpersonal problems remain a great burden. This reflects the highly stigmatised nature of living with HIV. 'Interpersonal problems' in the POS comprise two questions: 'have you been able to share how you are feeling' and 'have you had enough help and advice for your family to cope'. Non-disclosure of HIV status may have limited participants' opportunities to share feelings or provide their family with the right help. The need for emotional support has been shown to be a key motivator for disclosure to family members [31].

Poorer physical function was predictive of a worse response in physical health score and interpersonal problems. Given that late presentation with advanced disease is still relatively common [4], those with poorer function at diagnosis will require greater attention to achieve benefit from entering care and improvements in self-report wellbeing, and should be considered at increased risk. The finding may also reflect added barriers for people with disabilities [32].

In low- and middle-income countries, depression and other mental, neurological and substance use disorders are common among people living with HIV but diagnosis and treatment remains poor [33]. HIV service providers lack confidence and understanding of mental health care $[34,35]$. There is growing evidence that rather than being a task for specialist referral, lay health workers can be trained to manage common mental disorders in a primary care setting [36, 37], including care for people with HIV [38].

There are a number of limitations to our study. The cohort length of three months is relatively short, but it covers the crucial period immediately after diagnosis when decisions about care must be made and habits of adherence established [9]. CD4 count was missing from half the sample, almost entirely in Uganda, which, indicates non-random programmatic variation [28]. CD4 was not included in the multilevel models as it would have skewed the sample as well as reducing the sample size, which was already relatively small. Many variables that could affect multidimensional problems or quality of life were not collected and so could not be adjusted for. We note that poorer health-related quality of life and poorer mental health are associated with attrition from care [39], and therefore there is a risk of attrition bias in our sample which would cause outcomes to appear to improve over time. While the use of patient-reported outcomes is a strength of this study, patient-reported clinical details may be a limitation. ART data is patient-reported and clinically assessed ART eligibility was not recorded. We used consecutive sampling, which is non-probabilistic and can be biased, although it is more representative than most other convenience methods.

\section{Conclusions}

Our study has revealed that while improvements in patient-reported outcomes are experienced in the three months following HIV diagnosis, a high burden persists, particularly for psychosocial problems. The benefits of entering care are associated with socio-demographic characteristics such as country, age and poverty. The WHO definition of health, established in 1948, remains relevant: physical, psychological and social wellbeing [40]. Low-cost approaches to person-centred care should be considered for people on ART, especially given the highest burden of interpersonal problems [41]. While access to testing, treatment and care is expanding under current policy, it is important that the psychosocial aspect of HIV disease is not ignored [42].

\section{Abbreviations}

APCA: African Palliative Care Association; KEMRI: Kenya Medical Research Institute; PEPFAR: President's Emergency Plan for AIDS Relief; UNCST: Uganda National Council for Science and Technology; USG: United States Government; WHO: World Health Organisation

\section{Acknowledgements}

We are grateful to the United States Agency for International Development for funding this study under a sub-agreement GPO-A-00-03-00003-00, made under the authority provided to the University of North Carolina. The present study benefited from the participation of a wide range of partners, medical professionals, HIV specialists and palliative care researchers. The authors are grateful for the guidance provided by the Kenyan and Ugandan USG Country Teams. Finally we are grateful to the staff and patients at the participating facilities.

\section{Funding}

This study was funded by the United States Agency for International Development under a sub-agreement GPO-A-00-03-00003-00, made under the authority provided to the University of North Carolina. The funder had no role in the design of the study and collection, analysis, or interpretation of data or in writing the manuscript.

\section{Availability of data and materials}

The datasets used and/or analysed during the current study are available from the corresponding author on reasonable request.

\section{Authors' contributions}

VS analysed the data and wrote the first draft of the paper. JD, RAP and FM$\mathrm{P}$ contributed to study design, data acquisition and interpretation. EN contributed to data management and analysis. IJH contributed to study design and interpretation. RH was Principal Investigator and designed the original study and wrote the first draft of the discussion. All authors read, commented on and approved the manuscript.

Ethics approval and consent to participate

Ethical approval to undertake the study was received from the Uganda National Council for Science and Technology (UNCST, Ref SS 1964), the 
Kenya Medical Research Institute (Ref KEMRI/RES/7/3/1) and the College Research Ethics Committee at King's College London (Ref CREC/06/07-140). Subsequent tool changes following initial piloting were also approved. All participants gave written informed consent.

\section{Consent for publication}

Not applicable.

\section{Competing interests}

The authors declare that they have no competing interests.

\section{Publisher's Note}

Springer Nature remains neutral with regard to jurisdictional claims in published maps and institutional affiliations.

\section{Author details}

${ }^{1}$ London School of Hygiene and Tropical Medicine, Keppel Street, London WC1E 7HT, England. 'King's College London, Florence Nightingale Faculty of Nursing Midwifery and Palliative Care, Cicely Saunders Institute, Department of Palliative Care, Policy and Rehabilitation, Bessemer Road, London SE5 9PJ, England. ${ }^{3}$ African Palliative Care Association, P. O. Box 72518, Plot 95, Dr Gibbons Road, Makindye Kampala, Uganda. ${ }^{4} \mathrm{MWAPO}$ Health Development Group, Nairobi, Kenya.

Received: 11 May 2018 Accepted: 27 February 2019

Published online: 12 March 2019

\section{References}

1. UNAIDS. 90-90-90: an ambitious treatment target to help end the AIDS epidemic. Geneva: Joint United Nations Programme on HIV/AIDS; 2014.

2. Atun R, Bataringaya J. Building a durable response to HIV/AIDS: implications for health systems. J Acquir Immune Defic Syndr. 2011;57(Suppl 2):S91-5.

3. Unge C, Södergård B, Ekström AM, Carter J, Waweru M, llako F, et al. Challenges for scaling up ART in a resource-limited setting: a retrospective study in Kibera, Kenya. J Acquir Immune Defic Syndr. 2009:50(4):397-402.

4. Wakeham K, Harding R, Bamukama-Namakoola D, Levin J, Kissa J, ParkesRatanshi R, et al. Symptom burden in HIV-infected adults at time of HIV diagnosis in rural Uganda. J Palliat Med. 2010;13(4):375-80.

5. Perry S, Jacobsberg L, Card CA, Ashman T, Frances A, Fishman B. Severity of psychiatric symptoms after HIV testing. Am J Psychiatr. 1993;150(5):775-9.

6. Keogh P, Allen S, Almedal C, Temahagili B. The social impact of HIV infection on women in Kigali, Rwanda: a prospective study. Soc Sci Med. 1994;38(8):1047-53.

7. Selman L, Simms V, Penfold S, Powell RA, Mwangi-Powell F, Downing J, et al. My dreams are shuttered down and it hurts lots'--a qualitative study of palliative care needs and their management by HIV outpatient services in Kenya and Uganda. BMC Palliat Care. 2013;12(1):35.

8. Leserman J, Whetten K, Lowe K, Stangl D, Swartz MS, Thielman NM. How trauma, recent stressful events, and PTSD affect functional health status and health utilization in HIV-infected patients in the south. Psychosom Med. 2005:67(3):500-7.

9. Meursing K, Sibindi F. HIV counselling - a luxury or necessity? Health Policy Plan. 2000;15(1):17-23.

10. Sherr L, Nagra N, Kulubya G, Catalan J, Clucas C, Harding R. HIV infection associated post-traumatic stress disorder and post-traumatic growth--a systematic review. Psychol Health Med. 2011;16(5):612-29.

11. Simms VM, Higginson IJ, Harding R. What palliative care-related problems do patients experience at HIV diagnosis? A systematic review of the evidence. J Pain Symptom Manag. 2011:42(5):734-53 Epub 2011/05/31.

12. Simms V, Gikaara N, Munene G, Atieno M, Kataike J, Nsubuga C, et al. Multidimensional patient-reported problems within two weeks of HIV diagnosis in East Africa: a multicentre observational study. PLoS One. 2013; 8(2):e57203 Epub 2013/02/23

13. Harding R, Simms V, Penfold S, McCrone P, Moreland S, Downing J, et al. Multicentre mixed-methods PEPFAR HIV Care \& Support Public Health Evaluation: study protocol. BMC Public Health. 2010;10:584.

14. Harding R, Simms V, Penfold S, Downing J, Namisango E, Powell RA, et al. Quality of life and wellbeing among HIV outpatients in East Africa: a multicentre observational study. BMC Infect Dis. 2014;14(1):613.
15. Harding R, Simms V, Penfold S, McCrone P, Moreland S, Downing J, et al. Multicentred mixed-methods PEPFAR HIV care \& support public health evaluation: study protocol. BMC Public Health. 2010;10:584 Epub 2010/10/06.

16. Wu AW, Revicki DA, Jacobson D, Malitz FE. Evidence for reliability, validity and usefulness of the medical outcomes study HIV health survey (MOS-HIV). Quallife Res. 1997;6(6):481-93.

17. Stangl AL, Bunnell R, Wamai N, Masaba H, Mermin J. Measuring quality of life in rural Uganda: reliability and validity of summary scores from the medical outcomes study HIV health survey (MOS-HIV). Qual Life Res. 2012; 21(9):1655-63 Epub 2011/12/27.

18. Mast TC, Kigozi G, Wabwire-Mangen F, Makumbi F, Sewankambo NK, Serwadda D, et al. Cultural adaptation, reliability, validity and feasibility of the MOS-HIV health survey to measure quality of life in rural Uganda. XIII International AIDS Conference; 9-14 July 2000; Durban2000. p. Abstract no. MoOrD201.

19. Harding R, Selman L, Agupio G, Dinat N, Downing J, Gwyther L, et al. Validation of a core outcome measure for palliative care in Africa: the APCA African palliative outcome scale. Health QualLife Outcomes. 2010:8:10

20. Bowling A. Measuring disease: a review of disease-specific quality of life measurement scales. Bury St Edmonds: St Edmondsbury Press Limited; 2001.

21. Revicki DA, Sorensen S, Wu AW. Reliability and validity of physical and mental health summary scores from the medical outcomes study HIV health survey. MedCare. 1998;36(2):126-37.

22. Harding R, Selman L, Simms VM, Penfold S, Agupio G, Dinat N, et al. How to analyze palliative care outcome data for patients in sub-Saharan Africa: an international, multicenter, factor analytic examination of the APCA African POS. J Pain Symptom Manag. 2013;45(4):746-52. Epub 2012/09/29.

23. Siegert RJ, Gao W, Walkey FH, Higginson IJ. Psychological well-being and quality of care: a factor-analytic examination of the palliative care outcome scale. J Pain Symptom Manag. 2010;40(1):67.

24. Gwatkin DR, Rustein S, Johnson K, Pande RP, Wagstaff A. Socioeconomic differences in health, nutrition, and population in Ghana: World Bank; 2000.

25. Kenya National AIDS and STI Control Programme (NASCOP). Guidelines for antiretroviral drug therapy in Kenya. In: Nairobi; 2005

26. Mutabazi-Mwesigire D, Katamba A, Martin F, Seeley J, Wu AW. Factors that affect quality of life among people living with HIV attending an Urban Clinic in Uganda: a cohort study. PLoS One. 2015;10(6):e0126810.

27. Mwesigire DM, Martin F, Seeley J, Katamba A. Relationship between CD4 count and quality of life over time among HIV patients in Uganda: a cohort study. Health Qual Life Outcomes. 2015;13:144.

28. Harding $R$, Simms $V$, Penfold $S$, Downing J, Powell RA, Mwangi-Powell $F$, et al. The presence of CD4 counts for the management of HIV patients in East Africa: a multicentred study. AIDS Care. 2014;26(5):6138. Epub 2013/10/09.

29. Tomita A, Garrett N, Werner L, Burns JK, Mpanza L, Mlisana K, et al. Healthrelated quality of life dynamics of HIV-positive south African women up to ART initiation: evidence from the CAPRISA 002 acute infection cohort study. AIDS Behav. 2014;18(6):1114-23 Epub 2013/12/26.

30. Ramirez-Avila L, Regan S, Giddy J, Chetty S, Ross D, Katz JN, et al. Depressive symptoms and their impact on health-seeking behaviors in newlydiagnosed HIV-infected patients in Durban, South Africa. AIDS Behav. 2012; 16(8):2226-35 Epub 2012/03/28.

31. Maman S, van Rooyen H, Groves AK. HIV status disclosure to families for social support in South Africa (NIMH project accept/HPTN 043). AIDS Care. 2014;26(2):226-32

32. Parsons JA, Bond VA, Nixon SA. 'Are we not human?' stories of stigma, disability and HIV from Lusaka, Zambia and their implications for access to health services. PLoS One. 2015;10(6):e0127392.

33. Chibanda D, Benjamin L, Weiss HA, Abas M. Mental, neurological, and substance use disorders in people living with HIV/AIDS in low- and middleincome countries. Journal of acquired immune deficiency syndromes (1999). 2014;67 Suppl 1:S54-67.

34. Mall S, Sorsdahl K, Swartz L, Joska J. "I understand just a little" perspectives of HIV/AIDS service providers in South Africa of providing mental health care for people living with HIV/AIDS. AIDS Care. 2012;24(3):319-23.

35. Chorwe-Sungani G, Shangase N. Therapeutic commitment for general nurses in dealing with mental health problems of people living with HIV/ AIDS in Blantyre, Malawi. Malawi Med J. 2013;25(4):109-12.

36. Chibanda D, Weiss HA, Verhey $R$, Simms V, Munjoma R, Rusakaniko S, et al. Effect of a primary care-based psychological intervention on symptoms of common mental disorders in Zimbabwe: a randomized clinical trial. Jama. 2016;316(24):2618-26. 
37. Patel V, Weobong B, Weiss HA, Anand A, Bhat B, Katti B, et al. The healthy activity program (HAP), a lay counsellor-delivered brief psychological treatment for severe depression, in primary care in India: a randomised controlled trial. Lancet (London, England). 2017;389(10065):176-85.

38. Abas M, Nyamayaro P, Bere T, Saruchera E, Mothobi N, Simms V, et al. Feasibility and acceptability of a task-shifted intervention to enhance adherence to HIV medication and improve depression in people living with HIV in Zimbabwe, a low income country in sub-Saharan Africa. AIDS Behav. 2017.

39. Krumme AA, Kaigamba F, Binagwaho A, Murray MB, Rich ML, Franke MF. Depression, adherence and attrition from care in HIV-infected adults receiving antiretroviral therapy. J Epidemiol Community Health. 2015;69(3): 284-9.

40. World Health Organisation. Consitution of the World Health Organisation. 1948: http://www.who.int/governance/eb/who_constitution_en.pdf.

41. Lowther K, Selman L, Simms V, Gikaara N, Ahmed A, Ali Z, et al. Nurse-led palliative care for HIV-positive patients taking antiretroviral therapy in Kenya: a randomised controlled trial. Lancet HIV. 2015; Epub 15/06/2015.

42. Harding R, Downing J, Ekstrand M, Gwyther L, Sherr L. Evidence-based programming of HIV care and support: is the psychosocial "optional"? JAIDS. 2015;70(5):e176-e7.

Ready to submit your research? Choose BMC and benefit from:

- fast, convenient online submission

- thorough peer review by experienced researchers in your field

- rapid publication on acceptance

- support for research data, including large and complex data types

- gold Open Access which fosters wider collaboration and increased citations

- maximum visibility for your research: over $100 \mathrm{M}$ website views per year

At BMC, research is always in progress.

Learn more biomedcentral.com/submissions 